\title{
Predictors of Ownership/Utilisation Indicators of Long-lasting Insecticide Nets in the Bamendankwe Health Ar- ea of Cameroon: A Cross-Sectional Study
}

\author{
Nchang F. Cho ${ }^{1,2,3^{*}}$; Ngum P. Fru ${ }^{4,5^{*}}$; Fri S. Munguh ${ }^{6}$; Menyi B. Cho ${ }^{6}$; Kofon P. Jokwi ${ }^{6}$; Neh C. Fru ${ }^{7}$; Nde P. \\ Fon $^{4,8}$; Andrew Tassang ${ }^{9,10,11}$; Same A. Ekobo ${ }^{12,13}$ \\ ${ }^{I}$ Department of Biochemistry and Molecular Biology, Faculty of Science, University of Buea, Buea, Cameroon. \\ ${ }^{2}$ Infectious Disease Laboratory (IDL), Faculty of Health Sciences, University of Buea, Buea, Cameroon. \\ ${ }^{3}$ Central African Network for Tuberculosis, HIV/AIDs and Malaria (CANTAM), University of Buea, Buea, Came- \\ roon. \\ ${ }^{4}$ Department of Public Health and Hygiene, Faculty of Health Sciences, University of Buea, Buea, Cameroon. \\ ${ }^{5}$ District Health Service Tiko, South West Regional Delegation of Health, Ministry of Health, Cameroon. \\ ${ }^{6}$ Catholic School of Health Sciences, Saint Elizabeth Hospital Complex, Shisong-Nso, Cameroon. \\ ${ }^{7}$ Department of Sociology and Anthropology, University of Buea, Buea, Cameroon. \\ ${ }^{8}$ Solidarity Hospital, Buea-Cameroon. \\ ${ }^{9}$ Department of Obstetrics and Gynaecology, University of Buea, Buea, Cameroon. \\ ${ }^{10}$ Buea Regional Hospital Annex, Cameroon. \\ ${ }^{11}$ Atlantic Medical Foundation, Mutengene-Cameroon. \\ ${ }^{12}$ Faculty of Sciences, University of Yaoundé I, Yaoundé, Cameroon. \\ ${ }^{13}$ Faculty of Medicine and Pharmaceutical Sciences, University of Douala, Cameroon.
}

\begin{abstract}
*Correspondence should be addressed to Nchang F. Cho and Ngum P.Fru : nchang.cho@gmail.com; frupaulette@yahoo.com Received 27th October 2020; Revised 20th November 2020; Accepted 22nd November 2020

(C) 2020 Cho et al. Licensee Pan African Journal of Life Sciences. This is an Open Access article distributed under the terms of the Creative commons Attribution License (https://creativecommons. org/licenses/BY/4.0), which permits unrestricted use, distribution, and reproduction in any medium, provided the original work is properly cited.
\end{abstract}

\begin{abstract}
Background: Long-lasting Insecticide Nets (LLINs) are effective in the prevention of malaria, but universal utilisation continues to be declining in parts of Cameroon. This study aimed to explore the predictors and incidences of LLINs ownership/ utilisation in a semi-urban community in the Bamenda Health District (BHD). .

Methods: A cross-sectional survey involving 448 randomly selected household heads was conducted between March and April 2018 in the BHD. Data on LLINs ownership and utilisation were collected with structured questionnaires. Multivariate analysis was used to establish the predictors of LLINs utilisation and ownership.

Results: Household ownership of at least one LLINs and universal usage was $93.3 \%$ and $43.1 \%$ respectively.

Conclusion: The utilisation of LLINs was low and had no significant association with ownership. Continuous educational efforts and monitoring schemes with specific emphasis on vulnerable groups should be stepped up.
\end{abstract}

Keywords: Long-Lasting Insecticide Nets, Ownership of LLINs, Utilisation of LLINs, Predictors, Cameroon. 


\subsection{INTRODUCTION}

Malaria remains one of the greatest killer disease and threat to public health in Africa, despite all control strategies invested in by the World Health Organisation (WHO) and stakeholders to reduce it. In Africa, it accounted for about $91 \%$ of cases during the 2014 indicator survey and a devastating disease threatening the productivity and economy of endemic countries [1]. It accounted for up to $40 \%$ of public health expenditures, $30-50 \%$ of inpatient hospitalisations and up to $60 \%$ of outpatient health clinic visits, with an enormous and long -lasting effect on economic growth and development [15]. It is the leading cause of mother and child morbidity and mortality, accounting for more than $81 \%$ of reported cases, about $91 \%$ of the deaths, and the third major cause of death $(8.8 \%)$ in Cameroon $[1,6]$. Although the scaleup of effective prevention tools had a major impact in the fight against malaria, the WHO recommended two prevention strategies: vector control measures and preventive treatment strategies for the most vulnerable groups to reduce malaria morbidity and mortality $[4,5,7$, 8]. Vector control is the main approach to malaria prevention and transmission, two forms which are effective in a lot of circumstances are: insecticide-treated mosquito nets (ITNs)/ Long Lasting Insecticide Nets (LLINs) and Indoor Residual Spraying of Insecticides [1, $4,6]$. There are individual, household, and environmental barriers to LLINs usage as well as the low perception of malaria resulting in inconsistent use of the LLINs [9].

In 2011, over eight million LLINs were distributed in Cameroon in an effort to reduce the burden of malaria [5, 10]. Increasing the coverage and use of LLINs is the most promoted vector control prevention strategy in malaria-endemic countries, in line with the WHO recommendations [1, 11-14]. The free mass distribution campaign (MDC) of 2011 and 2015 has scaled up the ownership of LLINs, but the universal utilisation of LLINs does not match ownership [7], as malaria rates are still on the rise [1].

So far, there is limited data on LLINs ownership and utilisation within the Cameroonian population. The objective of this study was to determine the predictive factors affecting the ownership and the utilisation indicators of LLINs in the Bamendankwe community.

\subsection{METHODOLOGY}

\subsection{Study Design and Population}

This was a community-based cross-sectional study, carried out to evaluate the ownership and utilisation indicators and associated factors. This study was conducted from March to May 2018, in a semi-urban community, with an undulating topography, located to the East of Bamenda metropolis. The Bamendankwe Health Area is one of the 17 health areas in the Bamenda Health District.

Eligible participants were single or married persons of either male or female gender aged $\geq 20$ years who had resided in an household for at least the past 12 months.

\subsection{Sample Size Determination}

This study comprised household heads from eight localities of the community, with a minimum sample size of 356, calculated with the CDC- Epi-Info version 7.2.2.6 (Centre for Disease Control, Georgia USA) with the following characteristics; an average population of 307,620 in 2009 with an annual increase rate of $2 \%$ (6152.4) to 369,144 in 2018 [15] for the health district, an estimated proportion of households owning LLINs of $63.5 \%$ [2], an accepted error margin of 5\%, design effect of 1.0 and one cluster. Given the possibility of missing out on some of the households, the sample size was adjusted by a $10 \%$ loss to 392 . A total of 448 households were finally sampled.

\subsection{Variables and Definition of Concepts}

A household was defined as a wife with her direct dependents, and a compound was divided into several households depending on the number of wives, where the husband was assigned to the first wife's household [16, 17].

The ownership of LLINs was defined as the proportion of households with at least one LLIN, where the numerator comprises the number of households surveyed with at least one LLIN and the denominator, the total number of households surveyed. Coverage was the proportion of households with at least an LLIN for every two people, where the numerator comprises all households where the ratio between the number of LLINs owned and the number of de-jure members of that household, that is, usual members excluding visitors, is 0.5 or higher and the denominator is the total number of sampled households [18-20]. 
Table 1. Socio-demographic Characteristics of Study Participants

\begin{tabular}{|c|c|c|c|c|c|c|c|c|}
\hline \multirow[b]{2}{*}{ Variable } & \multirow[b]{2}{*}{ Subclass } & \multirow[b]{2}{*}{ n (\%) } & \multicolumn{3}{|c|}{ Coverage $(n=387)$} & \multicolumn{3}{|c|}{ Universal utilisation $(n=192)$} \\
\hline & & & No & Yes & $\chi^{2} / \mathbf{F}$ (p-value) & No & Yes & $\begin{array}{l}\chi^{2} / \mathbf{F}(\mathbf{p}- \\
\text { value) }\end{array}$ \\
\hline \multirow{3}{*}{$\begin{array}{l}\text { Age } \\
\text { groups } \\
\text { (in years) }\end{array}$} & $\leq 20$ & $9(2.2)$ & $3(9.7)$ & $6(1.6)$ & $10.82\left(4.48 \times 10^{-}\right.$ & $5(2.5)$ & $4(2.1)$ & $3.23(0.19)$ \\
\hline & $21-40$ & $282(67.5)$ & $16(51.6)$ & $266(68.7)$ & & $144(63.7)$ & $138(71.9)$ & \\
\hline & Mean age $( \pm$ SEM $)$ & $35.89 \pm 0.48$ & $35.32 \pm 2.07$ & $35.94 \pm 0.49$ & $10.87(0.738)$ & $\begin{array}{l}36.73 \pm 10 \\
06\end{array}$ & $\begin{array}{l}34.91 \pm 9.4 \\
8\end{array}$ & $\begin{array}{l}341.67 \\
(0.06)\end{array}$ \\
\hline Sex & Females & $258(61.7)$ & $2(6.5)$ & $256(66.1)$ & $\begin{array}{l}43.29\left(4.71 \times 10^{-}\right. \\
11 *)\end{array}$ & $135(59.7)$ & $123(64.1)$ & $0.82(0.36)$ \\
\hline $\begin{array}{l}\text { Marital } \\
\text { status }\end{array}$ & Married & $256(61.2)$ & $14(45.2)$ & $242(62.5)$ & & $135(59.7)$ & $121(63.0)$ & \\
\hline \multirow{3}{*}{$\begin{array}{l}\text { Educa- } \\
\text { tion }\end{array}$} & Primary & $138(33.0)$ & $9(29.0)$ & $129(33.3)$ & $0.42(0.81)$ & $72(31.9)$ & $66(34.4)$ & $2.07(0.36)$ \\
\hline & Secondary & $141(33.7)$ & $12(38.7)$ & $129(33.3)$ & & $72(31.9)$ & $69(35.9)$ & \\
\hline & Tertiary & $139(33.3)$ & $10(32.3)$ & $129(33.3)$ & & $82(36.3)$ & $57(29.7)$ & \\
\hline \multirow[t]{4}{*}{$\begin{array}{l}\text { Occupa- } \\
\text { tion }\end{array}$} & Agricultural & $147(35.2)$ & $12(38.7)$ & $135(34.9)$ & $8.67\left(3.4 \times 10^{-2} *\right)$ & $85(37.6)$ & $62(32.3)$ & $\begin{array}{l}11.45 \\
(0.01 *)\end{array}$ \\
\hline & Unskilled & $118(28.2)$ & $3(9.7)$ & $115(29.7)$ & & $55(24.3)$ & $63(32.8)$ & \\
\hline & State/ Parastatal & $29(6.9)$ & $5(16.1)$ & $24(6.2)$ & & $23(10.2)$ & $6(3.1)$ & \\
\hline & Professional & $124(29.7)$ & $11(35.5)$ & $113(29.2)$ & & 63 (27.9) & $61(31.8)$ & \\
\hline $\begin{array}{l}\mathrm{N}^{0} \text { of } \\
\text { bedrooms }\end{array}$ & $\begin{array}{l}\text { Mean } \mathrm{N}^{\mathrm{o}} \text { of bed- } \\
\text { rooms }( \pm \mathrm{SEM})\end{array}$ & $2.01 \pm 0.05$ & $2.07 \pm 0.06$ & $1.94 \pm 0.07$ & $1.70(0.19)$ & $2.07 \pm 0.06$ & $1.94 \pm 0.07$ & $1.70(0.19)$ \\
\hline \multirow{6}{*}{$\begin{array}{l}\text { House- } \\
\text { hold } \\
\text { Composi- } \\
\text { tion }\end{array}$} & $\begin{array}{l}\text { Mean } \mathrm{N}^{\mathrm{o}} \text { of chil- } \\
\text { dren }<5\end{array}$ & $1.07 \pm 0.05$ & $1.33 \pm 0.07$ & $0.76 \pm 0.06$ & $\begin{array}{l}37.80\left(1.84 \times 10^{-}\right. \\
\left.9_{*}^{*}\right)\end{array}$ & $1.25 \pm 0.07$ & $0.76 \pm 0.06$ & $\begin{array}{l}26.54 \\
\left(4.04 \times 10^{-7} *\right)\end{array}$ \\
\hline & $\begin{array}{l}\text { Mean } \mathrm{N}^{\circ} \text { of chil- } \\
\text { dren } 6-17\end{array}$ & $1.71 \pm 0.05$ & $1.96 \pm 0.07$ & $1.41 \pm 0.07$ & $\begin{array}{l}28.69 \\
7 *)\end{array}\left(1.41 \times 10^{-}\right.$ & $1.17 \pm 0.08$ & $1.41 \pm 0.07$ & $\begin{array}{l}4.80 \\
\left(2.90 \times 10^{-2} *\right)\end{array}$ \\
\hline & $\begin{array}{l}\text { Mean } \mathrm{N}^{\mathrm{o}} \text { of persons } \\
\geq 18\end{array}$ & $1.90 \pm 0.03$ & $2.0 \pm 0.04$ & $1.78 \pm 0.04$ & $\underset{4 *)}{15.18\left(1.14 \times 10^{-}\right.}$ & $0.76 \pm 0.06$ & $1.74 \pm 0.04$ & $\begin{array}{l}146.61 \\
\left(4.10 \times 10^{-29} *\right)\end{array}$ \\
\hline & $\begin{array}{l}\text { Expectant women } \\
\text { surveyed }\end{array}$ & $0.11 \pm 0.01$ & $0.11 \pm 0.02$ & $0.10 \pm 0.02$ & $0.04(0.833)$ & $0.07 \pm 0.02$ & $0.08 \pm 0.02$ & $\begin{array}{l}0.23 \\
\left(6.32 \times 10^{-1}\right)\end{array}$ \\
\hline & $\begin{array}{l}\text { Mean household } \\
\text { size }( \pm \text { SEM })\end{array}$ & $4.78 \pm 0.10$ & $5.41 \pm 0.14$ & $4.05 \pm 0.13$ & $\begin{array}{l}48.52\left(1.28 \times 10^{-}\right. \\
11 *)\end{array}$ & $3.25 \pm 0.14$ & $3.99 \pm 0.13$ & $\begin{array}{l}15.15 \\
\left(1.15 \times 10^{-4} *\right)\end{array}$ \\
\hline & $\begin{array}{l}\text { Population sur- } \\
\text { veyed }\end{array}$ & 2000 & 107 & 1893 & $\begin{array}{l}14.02\left(2.06 \times 10^{-}\right. \\
\left.4_{*}\right)\end{array}$ & 1222 & 778 & $\begin{array}{l}48.52 \\
\left(1.28 \times 10^{-11} *\right)\end{array}$ \\
\hline \multirow[t]{2}{*}{$\begin{array}{l}\text { Net Own- } \\
\text { ership }\end{array}$} & $\begin{array}{l}\text { Mean } N^{o} \text { of nets/ } \\
\text { household }\end{array}$ & $2.69 \pm 0.06$ & $1.06 \pm 0.06$ & $2.82 \pm 0.06$ & $\begin{array}{l}68.74\left(1.57 \times 10^{-}\right. \\
15 *)\end{array}$ & $3.05 \pm 0.08$ & $2.28 \pm 0.08$ & $\begin{array}{l}45.64 \\
\left(4.81 \times 10^{-11 *}\right)\end{array}$ \\
\hline & $\begin{array}{l}\text { LLINs : Person } \\
\text { ratio }\end{array}$ & $1126 / 2000$ & $33 / 107$ & $1093 / 1893$ & & $689 / 1222$ & $437 / 778$ & \\
\hline
\end{tabular}


The household universal LLINs utilisation was defined as the proportion of the population that slept under LLINs the previous night [18-20]. The utilisation of LLINs last night was defined as, the proportion of household heads who used LLINs the night before the survey, where the numerator comprises the number of household heads who used LLINs last night, and the denominator, the total number of household heads surveyed.

\subsection{Ethical Statement}

This study was approved by the Regional Delegation of Public Health for the Southwest region and the Faculty of Health Science Institutional Review Board, University of Buea, Cameroon (FHS-UB No: 624-05). Verbal permission was obtained from the local authorities of the localities where the study took place.

\subsection{Data Collection and Statistical Analysis}

Data were collected from heads of households in eight quarters of the community. The quarters were selected by simple random sampling, followed by the systematic sampling of households. Semi-structured questionnaires were used for data collection from each household head. The questionnaires were structured into the following sections: identification, ownership of LLINs, utilisation of LLINs and socio-demographic data. Statistical analysis was performed with Statistical Package for the Social Sciences version 25 (IBM-SPSS, Inc, Chicago, IL, USA). Associations between predictive factors and LLINs ownership/ utilisation were explored with Pearson Chi-square $\left(\chi^{2}\right)$ and logistic regression analyses. Statistical significance was set at $\mathrm{p} \leq 0.05$.

\subsection{RESULTS}

\subsection{Characteristics of Study Participants}

A total of 448 household heads [282 (62.9\%) females and 166 (37.1) males] aged $36.18 \pm 9.86$ years (range $20-58$ years) were surveyed. The ownership and utilisation of LLINs from the 448 heads of households are presented in Figure 1. Four hundred and eighteen (93.3\%) of the 448 household heads sampled, had at least one LLIN and were thus included in this analysis. All 418 were from eight quarters of the BHA and comprised of $38.3 \%$ males and $61.7 \%$ females. The mean ( \pm SEM) age of participants was $35.89 \pm 0.48$ years. Of the 2,000 residents who slept home last night, $447(22.3 \%)$ were children less than five years old and $45(2.2 \%)$ were expectant mothers.

The majority $(61.2 \%)$ of the participants were married, $35.2 \%$ were engaged in farming, educational distribution amongst the three educational strata were almost the same, while a huge majority lived in one - three bedroom houses [mean bedroom $( \pm$ SEM) of $2.01 \pm 0.05$ ], as well a mean ( \pm SEM) family size of $4.78 \pm 0.10$ (Table 1 ).

\subsection{Household LLINs Ownership Indicators and Sources}

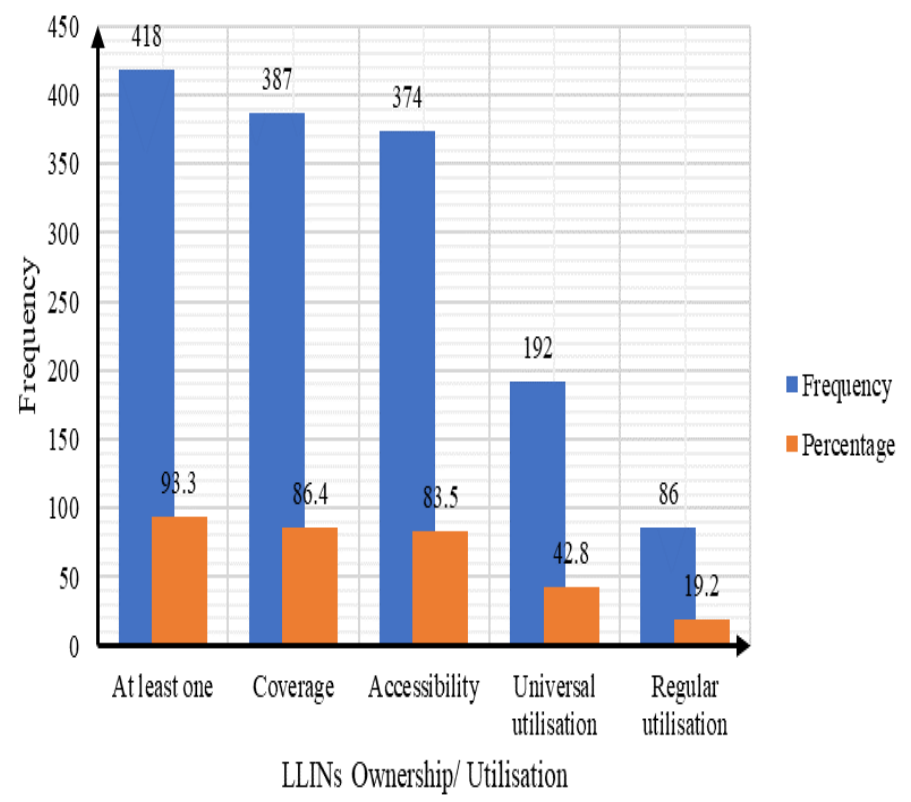

Figure 1. Household LLINs Ownership/ Utilisation Indicators

There were 1,126 LLINs, LLINs density (mean \pm SEM) of $2.69 \pm 0.06$, with overall household ownership of at least one LLINs and coverage proportions of $93.3 \%$ and $86.4 \%$ (LLIN: Person ratio of 0.56 ) respectively. Household accessibility to LLINs was $83.5 \%$ (Figure 1).

Long-lasting insecticidal nets were obtained from a variety of sources; $54.5 \%$ (228/418) from the free mass distribution campaigns, $22.5 \%$ (94/418) from the ante-natal clinic, $14.1 \%$ (59/418) from relatives, and 3.8\% (16/418) bought.

Household coverage (Table 1) was significantly associated with age, sex, marital status, occupation of the household head, and household size $(\mathrm{p}<0.05)$. Multivariate regression analysis (Table 2) revealed that marital and occupational statutes were independent predictors of household accessibility to LLINs and coverage. Households which were headed by unmarried persons were 
respectively about two and four folds more likely to have accessibility [O.R; $2.3,95 \%$ C.I; $(1.1-4.8), p=3.45 \times 10^{-}$ ${ }^{2}$ ] and coverage [O.R; 3.9, 95\% C.I; $(1.5-10.5), p=$ $6.53 \times 10^{-3}$ ] compared with those headed by married persons. For occupational status, households headed by state/parastatal workers were respectively about three and 5.5 folds more likely to have accessibility [O.R; $2.8,95 \%$ C.I; $(0.7-11.1), p=0.14$ ] and coverage [O.R; $5.5,95 \%$ C.I; $\left.(1.1-27.7), p=3.73 \times 10^{-2}\right]$ with LLINs when compared with the other occupations.

\subsection{Household Utilisation of LLINs}

One hundred and ninety-two [192 (42.8\%)] and 86 $(19.2 \%)$ of the 448 households sampled, slept under LLINs last night, and regularly used LLINs respectively (Figure 1).

The universal utilisation of LLINs (Table 1) was associ- ated with the age and occupational status of the household head $(\mathrm{p}<0.05)$. Multivariate analysis (Table 2$)$ showed that households whose heads were unmarried and state/parastatal employees were more likely to effectively [O.R; 1.5, 95\% C.I; $\left.(0.9-2.2), \mathrm{p}=8.80 \times 10^{-2}\right]$ and regularly [O.R; 2.0, 95\% C.I; $(1.1-3.8), p=1.44 \times 10^{-2}$ ] use LLINs when compared with their counterparts.

\subsection{The rationale for the ineffective utilisation of LLINs}

Table 3 shows 10 reasons for irregular utilisation of LLINs by study participants. Of these, only three (it gives heat, it is dirty and "no mosquitoes) were significantly associated with the regular utilisation of LLINs in the binary regression analysis. Those who said LLINs were allergic, that they lacked interest and that they usually forget, were $2.7,1.6$, and 2.5 times more likely to ineffec-

Table 2. Multinomial Logistic Analysis Showing the Association Between Predictors and LLINs Ownership/Utilisation Indicators

\begin{tabular}{|c|c|c|c|c|c|c|c|c|}
\hline \multirow{3}{*}{$\begin{array}{l}\mathbf{D V} \rightarrow \\
\mathrm{IV}^{-}\end{array}$} & \multicolumn{4}{|c|}{ Ownership of LLINs } & \multicolumn{4}{|c|}{ Utilization of LLINs } \\
\hline & \multicolumn{2}{|c|}{ Accessibility $(n=374)$} & \multicolumn{2}{|c|}{ Coverage $(n=387)$} & \multicolumn{2}{|c|}{ Universal $(n=192)$} & \multicolumn{2}{|c|}{ Regular $(n=86)$} \\
\hline & $p$-value & O.R (95\% C.I.) & $\mathrm{p}$-value & $\begin{array}{l}\text { O.R ( } 95 \% \\
\text { C.I. })\end{array}$ & p-value & O.R (95\% C.I. $)$ & $\begin{array}{c}\text { p- } \\
\text { value }\end{array}$ & $\begin{array}{l}\text { O.R }(95 \% \\
\text { C.I. })\end{array}$ \\
\hline $\begin{array}{l}\text { Age groups } \\
\text { (in years) }\end{array}$ & & & & & & & & \\
\hline$\leq 20$ & 0.17 & $3.4(0.6-20.3) \dagger$ & 0.22 & $\begin{array}{l}3.4(0.5- \\
24.4) \dagger\end{array}$ & 0.78 & $0.8(0.2-3.4)$ & - & - \\
\hline $21-40$ & 0.56 & $1.3(0.6-2.8) \dagger$ & 0.49 & $0.7(0.3-1.9)$ & $6.34 \times 10^{-2}$ & $0.6(0.4-1.0)$ & - & - \\
\hline $41-60$ & Ref & 1.0 & Ref & 1.0 & Ref & 1.0 & - & - \\
\hline Sex & & & & & & & & \\
\hline Females & $3.11 \times 10^{-6 *}$ & $0.2(0.1-0.3)$ & $1.89 \times 10^{-5} *$ & $\begin{array}{c}0.04(0.01- \\
0.2)\end{array}$ & 0.87 & $1.0(0.6-1.5)$ & 0.25 & $0.7(0.4-1.2)$ \\
\hline $\begin{array}{l}\text { Males } \\
\text { Marital } \\
\text { status }\end{array}$ & Ref & 1.0 & Ref & 1.0 & Ref & 1.0 & Ref & 1.0 \\
\hline Unmarried & $3.45 \times 10^{-2 *}$ & $2.3(1.1-4.8) \dagger$ & $6.53 \times 10^{-3} *$ & $\begin{array}{c}3.9(1.5- \\
10.5) \dagger\end{array}$ & $8.80 \times 10^{-2}$ & $1.5(0.9-2.2) \dagger$ & $\begin{array}{l}1.44 \mathrm{x} \\
10^{-2^{*}}\end{array}$ & $2.0(1.1-3.8)$ \\
\hline $\begin{array}{l}\text { Married } \\
\text { Education }\end{array}$ & Ref & 1.0 & Ref & 1.0 & Ref & 1.0 & Ref & 1.0 \\
\hline Primary & 0.86 & $1.1(0.4-2.9) \dagger$ & 0.63 & $\begin{array}{c}1.4(0.4-4.7) \\
+\end{array}$ & 0.81 & $0.9(0.5-1.6)$ & 0.81 & $\begin{array}{c}1.1(0.5-2.2) \\
+\end{array}$ \\
\hline Secondary & 0.48 & $1.4(0.6-3.4) \dagger$ & 0.45 & $1.6(0.5-5.1)$ & 0.80 & $0.9(0.6-1.6)$ & 0.20 & $0.7(0.4-1.2)$ \\
\hline $\begin{array}{l}\text { Tertiary } \\
\text { Occupation }\end{array}$ & Ref & 1.0 & Ref & 1.0 & Ref & 1.0 & Ref & 1.0 \\
\hline Agricultural & 0.24 & $1.6(0.7-3.8) \dagger$ & 0.22 & $\begin{array}{c}1.9(0.7-5.3) \\
\dagger\end{array}$ & 0.18 & $1.4(0.8-2.4) \dagger$ & 0.98 & $1.0(0.5-1.8)$ \\
\hline Unskilled & 0.44 & $0.6(0.2-2.0)$ & 0.41 & $0.5(0.1-2.4)$ & 0.60 & $0.9(0.5-1.5)$ & 0.33 & $\begin{array}{c}1.4(0.7-2.9) \\
+\end{array}$ \\
\hline $\begin{array}{l}\text { State/ Para- } \\
\text { statal }\end{array}$ & 0.14 & $2.8(0.7-11.1) \dagger$ & $3.73 \times 10^{-2} *$ & $\begin{array}{c}5.5(1.1- \\
27.7) \dagger\end{array}$ & ${ }_{2 *}^{1.12 \times 10^{-}}$ & $\begin{array}{c}3.7(1.4-10.4) \\
\dagger\end{array}$ & 0.34 & $\begin{array}{c}1.8(0.5-6.0) \\
\dagger\end{array}$ \\
\hline Professional & Ref & 1.0 & Ref & 1.0 & Ref & 1.0 & Ref & 1.0 \\
\hline $\begin{array}{l}\text { № of bed- } \\
\text { rooms }\end{array}$ & & & & & & & & \\
\hline $1-3$ & 0.15 & $0.5(0.2-1.3)$ & 0.70 & $0.8(0.2-3.1)$ & 0.28 & $1.5(0.7-3.0) \dagger$ & 0.49 & $1.3(0.6-3.0)$ \\
\hline $4-7$ & Ref & 1.0 & Ref & 1.0 & Ref & 1.0 & Ref & 1.0 \\
\hline
\end{tabular}

O.R: Odds ratio, Ref: Reference, DV: Dependent variable, IV: Independent variable, *Indicates significant $p-$ value, $\dagger$ Indicates likely groups, SEM: Standard Error of Mean 
Table 3. Association of LLINs Utilisation With Reasons for Irregular Utilisation

\begin{tabular}{llllllll}
\hline & & & & & Universal use & Regular use \\
\hline Variable & $\mathbf{n}(\%)$ & No & Yes & p-value & O.R (95\% C.I.) & p-value & O.R (95\% C.I.) \\
Gives heat & $360(86.1)$ & $198(87.6)$ & $162(84.4)$ & 0.40 & $0.5(0.1-2.7)$ & $0.04 *$ & $0.04(0.0-0.8)$ \\
Allergy & $357(85.4)$ & $197(87.2)$ & $160(83.3)$ & 0.24 & $2.7(0.5-14.5) \dagger$ & 0.72 & $1.6(0.1-18.8) \dagger$ \\
Breathing difficulties & $191(45.7)$ & $107(47.3)$ & $84(43.8)$ & 0.41 & $1.2(0.8-1.8) \dagger$ & 0.18 & $1.5(0.8-2.5) \dagger$ \\
Difficult to hang & $124(29.7)$ & $70(31.0)$ & $54(28.1)$ & 0.38 & $0.7(0.4-1.5)$ & 0.68 & $1.2(0.5-3.1) \dagger$ \\
Lack interest & $95(22.7)$ & $57(25.2)$ & $38(19.8)$ & 0.19 & $1.6(0.8-3.3) \dagger$ & 0.15 & $2.2(0.7-6.7) \dagger$ \\
Tiredness & $72(17.2)$ & $36(15.9)$ & $36(18.8)$ & 0.68 & $0.9(0.5-1.5)$ & 0.40 & $1.4(0.7-2.7) \dagger$ \\
Dirty & $24(5.7)$ & $15(6.6)$ & $9(4.7)$ & 0.41 & $1.4(0.6-3.4) \dagger$ & $0.04 *$ & $0.4(0.2-0.9)$ \\
Forgot & $19(4.5)$ & $14(6.2)$ & $5(2.6)$ & 0.09 & $2.5(0.9-7.2) \dagger$ & - \\
No mosquitoes & $15(3.6)$ & $8(3.5)$ & $7(3.6)$ & 0.80 & $1.1(0.4-3.3) \dagger$ & $0.02 *$ & $0.2(0.1-0.7)$ \\
Used repellent & $15(3.6)$ & $7(3.1)$ & $8(4.2)$ & 0.80 & $0.9(0.3-2.5)$ & 0.65 & $0.7(0.2-2.9))$ \\
& 418 & 226 & 192 & & & & \\
\hline
\end{tabular}

O.R: Odds Ratio; C.I: Confidence Interval

tively use LLINs compared to their counterparts. Meanwhile those allergic to LLINs, those with breathing difficulties, those with lack of interest and tiredness were more likely to use the LLINs irregularly when compared with their counterparts.

\subsection{Association of Ownership With Utilisation}

Only coverage had a significant association with the regular utilisation of LLINs (Table 4).

Table 4. Association of LLINs Ownership Indicators With Utilisation Indicators

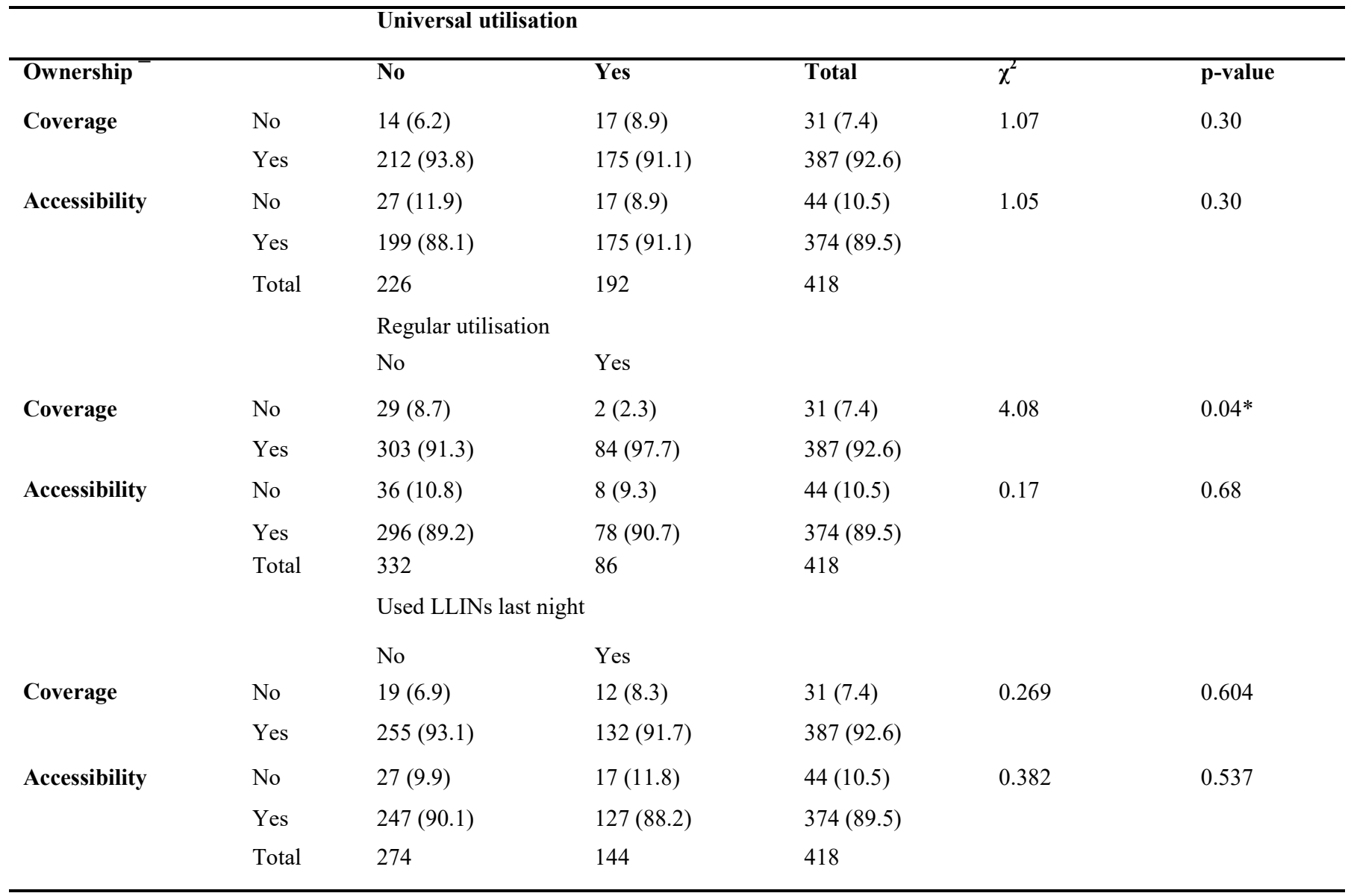




\subsection{DISCUSSION}

\subsection{Indicators of Household LLINs Ownership}

The aim of this study was to determine the LLINs ownership indicators, LLINs utilisation indicators and associated predictors of LLINs ownership/utilisation amongst household heads in the Bamendankwe Health area. LLINs ownership of $93.3 \%$ in this study was higher than the $47-89.9 \%$ reported elsewhere in Cameroon $[2,4$, $16,21-23$ ], the $33.3-85 \%$ in Africa [24-28], and the 15.5 $-48 \%$ in in Asia $[29,30]$. It was, however, lower than the $99.7 \%$ reported in Myanmar [31] and in line with the 93.5\% reported in Madagascar [27].

The $86.4 \%$ coverage (LLIN: Person ratio of 0.55 ) was higher compared to a similar study with $58.5 \%$ coverage in the Mount Cameroon area [23] and studies elsewhere around the world $[13,19,27,32]$ and lower compared to the Ministry of Public Health's ambition to achieve $100 \%$ coverage by 2015 [33] and another study in Myanmar [31]. Household LLINs accessibility of $83.5 \%$ observed in this study was higher compared to studies elsewhere in Africa [19, 27, 28, 34]. The differences could be attributed to the continuous efforts by the national malaria control programme to foster the ownership and utilisation of LLINs, study designs; hospital-based and community-based as well as study areas; in and out of Cameroon. The independent predictors of the ownership of at least one LLIN as well as coverage were marital status and occupation. Marital status was earlier reported in a similar study in the Bamenda Health area [2] wherein households headed by married individuals had a positive impact on LLINs ownership but differed from the findings of studies elsewhere in South-Eastern Nigeria, Ethiopia, Myanmar, and China [24, 25, 29, 31, 35] where it had no significant impact on ownership.

\subsection{Indicators of Household LLINs Utilisation}

The universal household utilisation of LLINs in the study of $43.1 \%$ was lower compared to reports elsewhere in Cameroon $[2,16,23]$ and in some places across the world [24, 27, 31, 32, 35] and higher when compared to the $21.5 \%$ reported in Ethiopia [25], 6.9 - 15.3\% in urban and rural Myanmar [30] and the $9.5-32.8 \%$ in Tanzania [28]. The $19.4 \%$ proportion of households regularly using LLINs in this study was very low compared to $48.0 \%$ reported in China [29] and 52.3\% in Ethiopia [26]. The low rate of LLINs utilisation in this study was also attributed to; heat $(86.6 \%)$, allergy $(85.9 \%)$, breathing difficulties $(46.7 \%)$, difficulties to install the nets $(29.7 \%)$, lack of interest (22.5\%) and tiredness (17\%). Compared to studies in Cameroon, these were higher: heat discomfort (26.7 - 52.2\%), difficulties hanging up nets (12.1 $25.3 \%)$ tiredness and laziness $(18.9 \%)[2,4,23]$ as well as negligence (29.3\%) [2] and environmental factor [36] accounting for non-usage of bed nets. Out of Cameroon, the rationale for the irregular and ineffective utilisation of LLINs was attributed to; the nets were too hot, difficulties in the installation, inconveniences, and lack of space $[9,29]$. These differences could be attributed to different study populations and study areas as well as different study seasons.

The independent determinants of the utilisation of LLINs were marital status, and occupation of the household head. Age, sex, education house type/number of bedrooms, environmental factor and ownership of LLINs had no significant association with the utilisation of LLINs. Occupation as observed in this study was in line with studies reported in Myanmar and China [29, 31].

Strengths of the study; field data were obtained by welltrained field surveyors and health personnel, with a mastery of the study area. The quality of data collected was assured through the pretesting of questionnaires in a pilot study to minimize bias.

Limitations of the study; this was a cross-sectional study, representing the snapshot of the population within the study period and does not show cause and effect since the predictor and outcome variables were measured at the same time. Data was collected through self-reporting and thus there is a possibility of bias where the respondent provides socially acceptable answers. Recall bias can also affect some of the responses and subsequently the results of the study. Also, the design of this study could not capture data on behaviour change communication and other malaria control measures. The study could not also capture data on the undulating nature of the different localities.

Although the free Mass Distribution Campaign, MDC has improved LLINs ownership and coverage, the universal utilisation of $43.1 \%$ is still very low. Factors that were significantly associated with the utilisation of LLINs were: the occupation of household head, household composition, and ownership of LLINs. Marital status and occupation were observed to be the independent predictors of ownership and utilisation of LLINs. Continuous educational efforts and monitoring schemes with specific emphasis on vulnerable groups should be stepped up. 


\section{Conflict of Interest}

The authors declare that there is no conflict of interest.

\section{Acknowledgements}

We are thankful to the heads of households who participated in this survey, the community health workers and to the field assistants who worked under challenging field conditions

\section{Authors Contribution}

NFC conceived and designed the study, performed data collection, analysed data and drafted the manuscript; NPF contributed to study design, data collection and manuscript writing ; FSM, MBC contributed to data collection and manuscript writing; KPJ contributed to data analysis and writing of the manuscript; NCF contributed to manuscript draft; NPF contributed to study design. All authors approved the final version of the manuscript

\section{References}

1. WHO. Malaria. In: News room; Fact sheets, editor. Switzerland: World Health Organisation; 2018.

2. Fokam EB, Kindzeka GF, Ngimuh L, Dzi KTJ, Wanji S. Determination of the predictive factors of long-lasting insecticide-treated net ownership and utilisation in the Bamenda Health District of Cameroon. BMC Public Health. 2017;17(263):1 - 10.

3. MOH. Plan Stratégique National de Lutte contre le Paludisme: 2014-2018. Ministère de la Santé Publique, Cameroun. In: Programme Nationale de Lutte contre le Paludisme, editor. Yaoundé: Programme National de Lutte contre le Paludisme; 2014.

4. Ntonifor NH, Veyufambom S. Assessing the effective use of mosquito nets in the prevention of malaria in some parts of Mezam division, Northwest Region Cameroon. Malar J. 2016;15(390):1 - 8.

5. Fokam EB, Dzi KTJ, Ngimuh L, Enyong P. The Effect of Long-Lasting Insecticide Bed Net Use on Malaria Prevalence in the Tombel Health District, South West RegionCameroon. Hindawi Publishing Corporation Malaria Research and Treatment. 2016; 2016:1 - 6 .

6. MOH. Health Analytical Profile 2016 Cameroon. Yaoundé Observatoire National de la Sante Publique; 2017. p. 1 -120 .

7. WHO. Malaria prevention works: Let's close the gap. In: WHO Global Malaria Programme, editor. World Malaria day 2017. France: World Health Organization; 2017. p. 1 -24 .

8. NIS. Demographic and Health survey and Multiple Indicators Cluster Survey DHS-MICS 2011. Preliminary report. Yaoundé, Cameroon: National Institute of Statistics;
2012.

9. Sangaré LR, Weiss NS, Brentlinger PE, Richardson BA, Staedke SG, Kiwuwa MS, et al. Determinants of Use of Insecticide Treated Nets for the Prevention of Malaria in Pregnancy: Jinja, Uganda. PLoS One. 2012;7(6): e39712.

10. Malaria No More. Cameroon Malaria Knowledge, Attitudes, and Practices. Malaria no more. Final Report, August 2012. In: Bowen H, editor. Progress from 2011 to 2012. New York: Malaria No More; 2012. p. 1 - 37.

11. Obala AA, Mangeni JN, Platt A, Aswa D, Abel L, Namae $\mathrm{J}$, et al. What Is Threatening the Effectiveness of Insecticide-Treated Bednets? A Case-Control Study of Environmental, Behavioral, and Physical Factors Associated with Prevention Failure. PLoS One. 2015;10(7): e0132778.

12. Moon TD, Hayes CB, Blevins M, Lopez ML, Green AF, González-Calvo L, et al. Factors associated with the use of mosquito bed nets: results from two cross-sectional household surveys in Zambézia Province, Mozambique. Malar J. 2016;15(196):1 - 10.

13. Zegers de Beyl C, Koenker H, Acosta A, Onyefunafoa EO, Adegbe E, McCartney-Melstad A, et al. Multicountry comparison of delivery strategies for mass campaigns to achieve universal coverage with insecticidetreated nets: what works best? Malar J. 2016;15(58):1 14.

14. WHO. Insecticide-treated nets: A WHO Position Statement on ITNs. In: Programme WGM, editor.: World Health Organisation; n.d. p. 1 - 12.

15. NIS. 2nd Survey on the Monitoring of Public Expenditures and the Level of Recipients' Satisfaction in the Education and Health Sectors in Cameroon (PETS2). Yaoundé National Institute of Statistics; 2010.

16. Kimbi HK, Nkesa S, Ndamukong-Nyanga JL, Sumbele IUN, Atashili J, Atanga MBS. Socio-demographic factors influencing the ownership and utilization of insecticidetreated bed nets among malaria vulnerable groups in the Buea Health District, Cameroon. BMC Res Notes. 2014;7 (624): 1 - 8 .

17. Wanzira H, Eganyu T, Mulebeke R, Bukenya F, Echodu $\mathrm{D}$, Adoke Y. Long lasting insecticidal bed nets ownership, access and use in a high malaria transmission setting before and after a mass distribution campaign in Uganda. PLoS One. 2018;13(1): e0191191.

18. CDC. Household Survey Indicators for Malaria Control. In: United States Agency for International Development, editor. USA: CDC, USAID, President's Malaria Initiative, RBM, UNICEF, WHO; 2013. p. 1 - 61.

19. Kilian A, Koenker H, Baba E, Onyefunafoa EO, Selby RA, Lokko K, et al. Universal coverage with insecticide- 
treated nets - applying the revised indicators for ownership and use to the Nigeria 2010 malaria indicator survey data. Malar J. 2013;12(314):1 - 12.

20. Polec LA, Petkovic J, Welch V, Ueffing E, Ghogomu ET, Pardo JP, et al. Strategies to Increase the Ownership and Use of Insecticide-Treated Bednets to Prevent Malaria. Cochrane Database of Systematic Reviews. 2015;17(3):1 129.

21. Apinjoh TO, Anchang-Kimbi JK, Mugri RN, Tangoh DA, Nyingchu RV, Chi HF, et al. The Effect of Insecticide Treated Nets (ITNs) on Plasmodium falciparum Infection in Rural and Semi-Urban Communities in the South West Region of Cameroon. PLoS One. 2015;10(2): e0116300.

22. Oyekale AS. Do Ownership of Mosquito Nets, Dwelling Characteristics and Mothers' Socio-Economic Status Influence Malaria Morbidity among Children under the age of 5 in Cameroon? Int J Occup Med Environ Health. 2015;28(3):479-97.

23. Njumkeng C, Apinjoh TO, Anchang-Kimbi JK, Amin ET, Tanue EA, Njua-Yafi C, et al. Coverage and usage of insecticide treated nets (ITNs) within households: associated factors and effect on the prevalence of malaria parasitemia in the Mount Cameroon area. BMC Public Health. 2019;19(1216):1 - 11 .

24. Russell CL, Sallau A, Emukah E, Graves PM, Noland GS, Ngondi JM, et al. Determinants of Bed Net Use in Southeast Nigeria following Mass Distribution of LLINs: Implications for Social Behavior Change Interventions. PLoS One. 2015;10(10): e0139447.

25. Biadgilign S, Reda A, Kedir H. Determinants of Ownership and Utilization of Insecticide-Treated Bed Nets for Malaria Control in Eastern Ethiopia. J Trop Med. 2012; 2012:1 - 7 .

26. Watiro AH, Awoke W. Insecticide-treated net ownership and utilization and factors that influence their use in Itang, Gambella region, Ethiopia: cross-sectional study. Risk Management and Healthcare Policy. 2016;6(9):101-12.

27. Finlay AM, Butts J, Ranaivoharimina H, Cotte AH, Ramarosandratana B, Rabarijaona $\mathrm{H}$, et al. Free mass distribution of long-lasting insecticidal nets lead to high levels of LLIN access and use in Madagascar, 2010: A cross- sectional observational study. PLoS One. 2017;12(8): e0183936.

28. Mboma ZM, Overgaard HJ, Moore S, Bradley J, Moore J, Massue DJ, et al. Mosquito net coverage in years between mass distributions: a case study of Tanzania, 2013. BMC Malaria Journal. 2018;17(100):1 - 14.

29. Xu J-w, Liao Y-m, Liu H, Nie R-h, Havumaki J. Use of Bed Nets and Factors That Influence Bed Net Use among Jinuo Ethnic Minority in Southern China. PLoS One. 2014;9(7): e103780.

30. Aung Tin, Wei Chongyi, McFarland Willi, Aung Ye Kyaw, Khin HSS. Ownership and Use of Insecticide-Treated Nets among People Living in Malaria Endemic Areas of Eastern Myanmar. PLoS One. 2016;11(9).

31. Liu H, Xu J-w, Guo X-r, Havumaki J, Lin Y-x, Yu G-c, et al. Coverage, use and maintenance of bed nets and related influence factors in Kachin Special Region II, northeastern Myanmar. Malar J. 2015;14(212):1 - 12.

32. Wanzira H, Katamba H, Rubahika D. Use of long-lasting insecticide-treated bed nets in a population with universal coverage following a mass distribution campaign in Uganda. Malar J. 2016;15(311):1 - 8 .

33. MOH. Regional Malaria Control Programme. Training of Key Actors for 2015 Mass Distribution Campaign in the South West Region. In: Regional Delegation for the Ministry of Public Health, editor. Bamenda: National Malaria Control Programme; 2015.

34. Clark S, Berrang-Ford L, Lwasa S, Namanya D, Twesigomwe S, IHACC Research Team, et al. A Longitudinal Analysis of Mosquito Net Ownership and Use in an Indigenous Batwa Population after a Targeted Distribution. PLoS One. 2016;11(5): e0154808.

35. Alemu MB, Asnake MA, Lemma MY, Melak MF, Yenit MK. Utilization of insecticide treated bed net and associated factors among households of Kola Diba town, North Gondar, Amhara region, Ethiopia. BMC Res Notes. 2018;11(575):1 - 5 .

36. Tchinda HM, Socpa A, Keundo AA, Zeukeng F, Seumen CT, Leke RGF, et al. Factors associated to bed net use in Cameroon: a retrospective study in Mfou health district in the Centre Region. Pan Afr Med J. 2012:1 - 10. 